ANDRZEJ PITRUS

Faculty of Management and Social Communication Jagiellonian University in Crakow, Poland

\title{
Artists play games
}

\begin{abstract}
Pitrus Andrzej, Artists play games. "Images" vol. XXIX, no. 38. Poznań 2021. Adam Mickiewicz University Press. Pp. 113-122. ISSN 1731-450X. DOI 10.14746/i.2021.38.07.

Andrzej Pitrus discusses complex relationships between the two worlds - art and computer/games. Numerous artists are looking for inspirations in the world of an interactive entertainment, yet some of them are creating new paths of its development. Some of the artists focus on new and unique interfaces. Others refer to the mechanics of games to create their own interactive works. Bill Viola's The Night Journey is an excellent example of such project. The author also reviews critical games, which are based on the mechanisms easily found in commercial games. Yet, their goal is to deconstruct them, rather than followig well known tracks. Pitrus examines this strategy in the works of a famous studio "Tale of Tales".
\end{abstract}

KEYWORDs: media art, video games, interactivity, interface

Strategies usually found in games are present in many areas of human life, not only as entertainment, but also as a convenient and effective tool of education, medical rehabilitation, problem-solving, communication between people and machines, and many others.[1] Relationships between art and games are also complex, as artists refer to them in many ways: using their mechanics and criticizing and deconstructing them, as well as redefining the gamer's experience. The boundaries between the two worlds are often blurred, as life as such becomes more and more "gamified." [2] It is not common knowledge that numerous technologies used every day are also found in games, while gamers sometimes do not notice that so many elements of their entertainment come from quite unexpected areas, including eg. the military, science and also art.

Artists often focus on experimentation. This is why they are often able to discover subversive uses of gaming interfaces and game mechanics, as well as to develop strategies which are sometimes later used in the more commercialized environment.

This comparative essay explores several examples of this complex relationship, presenting selected strategies observed in the works of artists belonging to the tradition of media art.

We live in a world of computer-based interfaces, and even common everyday-use devices seem to depend on them. But it is not only television sets that are state-of-the-art multimedia platforms; air-con-
Images vol. XXIX/no. 38

Poznań 2021

ISSN 1731-450x
[1] See: M. Ma, A. Oikonomou, et al., Serious Games and Edutainment Applications, London - Dordrecht New York 2011.
[2] P. Jagoda, Experimental Games: Critique, play, and design in the age of gamification, Chicago - London 2020 . 
ditioners, intelligent home gadgets, and even fridges can be accessed remotely, and they are also able to communicate with other machines. Some of those innovative interfaces were developed and designed by artists to be later used in game entertainment.

Interactivity allows audiences to take control of the final shape of the artwork. It also encourages audiences to pursue a performative approach[3]. Nowadays, we often deal with fully open projects; works of art take on lives of their own, evolving into forms that even their creators could not imagine. Grahame Weinbren's works seem simple, but without them, the shape of modern technological art might have been completely different.

The Erl King (1983-1986) was created thanks to the use of technologies allowing for saving video sequences in the form of a database to be played back later in a non-linear manner. Another new technology used by Weinbren was the touch screen. Although works on this type of interface began in the 1960s, it was released commercially as late as 1983 . It was then implemented to a CRT monitor, which allowed to create an illusion of direct control over the image. The users could interact with the objects presented on the monitor and trigger preprogrammed sequences. Weinbren referred to a piece composed in 1815 by Franz Schubert for the famous poem by Goethe, performed by singer Elizabeth Arnold with the accompaniment of pianist Dean Johnson. The recording of the performance was displayed on the monitor, and the audience could switch between several modes, additionally receiving commentary on the composition and its fictional visualization.

Although it was possible to navigate through the text, its elements remained unchanged and were often located in predetermined mutual relations. Moreover, the recipient of the work had to actively use the interface. The same basic structure can be found in early video games, where interactivity is limited by the preprogrammed content, and the system only functions when activated by a kind of symbolic interface in which certain actions cand be achieved by pressing corresponding buttons and/or moving a joystick or any other pointing device.

Grahame Weinbren was looking into the possibility of making the interface transparent, so that people using it did not have to have any competencies needed to launch and use it, and so that they could forget about its existence. In some of his later works, he achieved some success. His work Frames (1999) is based on photos taken by Hugh Diamond, which depict psychiatric hospital patients. The interface is made of empty picture frames equipped with infrared sensors, allowing for tracking the movement of the viewers' hands, manipulating the visual material. Meanwhile, The Tunnel (2000) is a significant step forward in interface development whereby viewers walk along a ramp while surrounded by

[3] S. Broadhurst, J. Machon, Performance and Technology: Practices of virtual embodiment and interactivity, Houndmills - New York 2011. 
images. The projections, which depict miners at work and a virtual fire erupting around them, are under their feet, but also on the ceiling. The artist's latest works are not as innovative as those created in the last two decades of the $20^{\text {th }}$ century, but Weinbren, along with Luc Courchesne, will probably forever remain the father of modern interactive art. Courchesne, who hails from the French-speaking part of Canada, was also interested in the possibilities of using laserdiscs in art. Elastic Movies (1984) proved that non-linear access to material recorded on discs may not only have a practical value, allowing for the construction of audiovisual databases, but can also be used to create individualized narratives, which are an alternative to the classical cinema, where the course of events on the screen is not negotiable. Echoes of Graham Weinbren and his experiments are present in a slightly forgotten line of the design of video games. When a larger storage medium (CD-ROM) became available, games could include more and more data, often in the form of digitized film sequences activated by the player. One of the most famous examples is Phantasmagoria, developed by Sierra Entertainment in 1995.

Courchesne, unlike Grahame Weinbren, did not focus on the possibility of creating new narrative forms, but confronted his interest in new technologies with his earlier fascinations in the art of portraiture, which is why many of his works rely upon the experience of dialogue with them. Portrait One (1990) is perhaps one of the most recognizable works of media art, although today this work may seem very anachronistic in terms of technology. The project is available in two versions; originally it was an installation intended for exhibition in a gallery, and later, the artist made it available in CD-ROM format to enable a more intimate interaction with it. The installation resembles an ATM and allows one to choose from many contextual options. The user's questions and answers have been predefined. This strategy is still used in many video games to introduce dialogue. The examples of the use of natural language to communicate with the in-game characters are still sparse, while a "multiple choice" option dating back to the times of early interactive art still does its job pretty well.

Courchesne did not have the opportunity to take advantage of AI technologies, but his work, which is an example of closed interactivity, undoubtedly inspired contemporary implementations based on the use of chatbots, both in art and video games.

A fascination with painting, and specifically panoramas, are reflected in Landscape One (1997). The viewer stands in the middle of four screens which display images recorded in one of the parks in Montreal. After some time, passers-by appear on the screens, and the viewer can either be an observer or interact with the strangers, foster relationships, and encourage them to interact or walk with them through the virtualized space. In 1997, the net-based game-like environment Second Life was yet to be released (it premiered in 2003), but the similarities between the projects are such that it can be seen as a modern version of Luc Courchesne's landscape. 
Courchesne created an installation that brings him closer to introducing natural language into the sphere of dialogue between people and technology. The Visitor: Living by Numbers allows users to navigate the space captured by a $360^{\circ}$ camera mounted on a mobile platform moving around a small village in Japan. The database of digitized movies can be explored using simple language. We no longer need to use an interface that reveals the conventionality of the relationship between man and technology; instead, the audience is encouraged to use a simple "language" consisting of numbers from 1 to 12 , assigned to specific vehicle movements. It seems that the code invented by the artist is more than simple, but the possibilities of the system are surprisingly numerous. You can spend hours in a peculiar chalice, which is also a screen on which images are displayed.

Explorations of the interface, which precede the technologies of the Nintendo Wii, XBOX, and other augmented reality platforms, can also be found in the works of Masaki Fujihata. AR is a kind of experience in which the physical world blends with images or sounds coming from the realm of virtuality. A fine example of his experimentation is his most famous and popular work from 1995, Beyond Pages. [4] It is an immersive environment located in a darkened room, where on a table one can find a book of Japanese writing and drawings. Although it looks like a real book, it is no more than a projection. Visitors can explore it using a light pen, which allows them to flip the pages and play with virtual and real-life objects.

Fujihata experimented with other technologies now popular in games, including locative media, allowing the player to adjust her or his experience to the actual location in time and space. Velocity (1994), the first of many fieldworks he created later, is considered to be the most important work of this period. The project took place in Mount Fuji, which, according to tradition, is a place that every Japanese citizen should visit at least once in their lifetime. Fujihata and his colleagues went there with a small camera and a GPS receiver, which allowed them to create a virtual portrait of their expedition.

Let's create

Another well-known project by Masaki Fujihata was created together with composer Kiyoshi Furukawa and programmer Wolfgang Münch. Their work now exists in several variants: as an application for home use and as an instrument used during performances by professional musicians. There is also an application for mobile devices with a touch screen.

In Small Fish (first implemented in 1999), we will not find competitive elements, yet it features a game-like interface similar to so-called serious games using fun-oriented mechanics for educational purposes,

[4] A different augmented reality book was published later for individual use. See: M. Fujihata, Anarchive $n^{\circ} 6$ - Masaki Fujihata,Paris 2016. This book was printed on paper but requires an iOS mobile device to fully explore its content. 
such as 2014's Rocksmith. Unlike Activision's Guitar Hero (first version: 2005) which uses the toy-like interface, UbiSoft's game lets the user play actual instruments (guitar and bass guitar) and gain some skills to be used later, without its aid. Small Fish also can be understood as a fully-functional musical device. The only difference is that it does not imitate any existing instrument, offering an alternative approach to sound design. The user can choose from numerous graphic interfaces and manipulate various virtual objects, which generate sounds when they collide.

Another artist interested in making music with game-like interfaces also comes from Japan. In the past, Toshio Iwai was interested in experimental animation, and his master was Norman McLaren, who, in many of his works, explored possible relationships between sound and vision. Many of Iwai's works also refer to this area, while others are art house games available for platforms such as PlayStation, Nintendo DS, and more.

Iwai's first work after graduation was the game Otocky (1987). The game itself is a platformer using well-known mechanics based on shooting at moving objects. The innovation of the project was that this simple shoot'em up was also a kind of musical instrument. Missiles fired in eight directions generated eight corresponding sounds. The live soundtrack created by the players is the first-ever example of so-called generative music in the game.[5]

During Iwai's stay in San Francisco, further works of a similar nature were created. One of them was Music Insects (1992), resembling a bitmap graphics program. Shapes and colours are equipped with additional functions, and virtual insects moving between them trigger sound sequences. In SimTunes (1996), a game intended for children, users painted the characters with pixels assigned to individual notes in the octave. Their creations interacted with virtual objects triggering musical phrases during collisions with drawings. Electroplankton (2005) was also primarily addressed to children, but in Japan, where portable platform Nintendo DS was very popular, it also attracted adult gamers. The game uses a more complex interface, in which the player can use a microphone, to include simple samples in their compositions. The most famous of Iwai's devices is Tenori-on (2005), designed with the support of Yamaha. It is a kind of tablet equipped with a matrix of 256 LED-backlit buttons. The artist presented his invention, among others, at the Ars Electronica festival in 2006, but it was popularized primarily by professional musicians using Tenori-on during concerts. For example, it was played by Jim O'Rourke, known as a soloist and member of Sonic Youth, as well as Icelandic musician Björk.[6] The device resembles a dedicated interface used in many games, while also functioning as a toy.

[5] The term refers to a compositional technique in which the co-author of the music is a machine properly prepared and programmed by the composer. This technique was used by Steve Reich, and pio- neered by John Cage. See: W. Phillips, A Composers Guide to Game Music, Cambridge 2017.

[6] She also played a Reactable (2007) by Marcos Alonso, Martin Kaltenbrunner, Günter Geiger and 
Anti-game and critical play
Relationships between games and art can also be observed in projects aimed at critical redefining of several aspects of game mechanics. Games created by the Belgian artist duo "Tale of Tales" (Auriea Harvey and Michael Samyn) are a fine example of anti-mechanics. Numerous releases from this now Rome-based studio are examples of negotiation of the deepest structures present in most commercial games. I would like to focus on two of them.

Graveyard (2008) is a miniature game which only takes minutes to complete. An old lady enters a graveyard, apparently to visit a deceased relative. At the end of the path, she takes a rest on a bench while listening to a song in Flemish. Thereafter, she heads back to the gate and the game terminates.

It is important to note that this atmospheric black and white game is available in two versions. The basic one can be downloaded free from the duo's website, while the full version comes with a fee, although the price is not extortionate. This strategy is quite common, especially when it comes to smaller projects. A fully-paid for version usually removes ads, and/or opens new levels and features. Here, a paying gamer can find only one difference: while in the free game the old lady is immortal, and is always able to visit the graveyard and safely return to its gate, in the "full" version, she loses this feature. However, her life is not threatened by monsters or armed opponents; she simply dies when a player forces her to move too fast.

This project tries to reexamine not only the mechanics usually found in games, but also its monetary context.[7] For their reward, the players get a more "realistic" version, instead of upgrading their ability to survive and win.

"Tale of Tales" also decided to comment on the growing business of multiplayer games. Although there are still examples of single-player triple-A productions, many of the big-budget games are available - at least as an option - as projects intended for many players gaming online at the same time. Games are thus sometimes more than a form of competitive entertainment; they become a social forum, where many external and internal channels of communication are employed.

The Endless Forest, first released in 2006, is an example of an anti-social media. It was probably influenced by Second Life and replicates its mechanics on a smaller scale. The player is encouraged to adopt an avatar that can later be used to interact with other gamers. Unlike Second Life, this web-based game does not offer any freedom, and its characters are reminiscent of deer, rather than humans. As such, they are unable to speak. The player has to assume the identity of an animal to interact with other members of the network. "Tale of Tales" seems to be one of the most productive and innovative teams of game
Sergio Jordà; an interactive table, where sounds are created by moving small cubicles with built-in microchips.
[7] A review of the subject can be found here: V. Lehdonvirta, E. Castronova, Virtual Economies: Design and analysis, Cambridge 2014. 
critics, but there are also other artists who successfully try to redefine the very definition of a game.

Bill Viola's The Night Journey[8] (2018) is another interesting example of an anti-game. The artist, known mostly for his video installations, does not aim at the deconstruction of game mechanics; instead, he uses a formula often found in open-space sandbox games to translate his obsessions into the language of interactive art. For Viola enthusiasts, The Night Journey came as a surprise, as only a few of his earlier works were interactive. Here, for the first time, an artwork was to be explored and enjoyed not in a gallery, but the privacy of a player's home.[9]

Before proceeding with the game, the interactant receives instructions very similar to those offered to the user of commercial games. The only difference is that there are much fewer pointers, as Bill Viola uses a minimalistic interface: only two analogue sticks are active (movement and camera position), along with the $\mathrm{X}$ button, which is assigned to a slightly mysterious function called "reflect”. There are no opponents in the game, which is a very important feature of Viola's implementation. In commercial games, the opposite is the norm, where players interact with virtual beings. In most cases, it is combat confrontation, although not always. Here, the user's only partner is a virtual space in which she or he can roam freely.

Bill Viola's "game" uses - despite the aforementioned minimalism - all the possibilities of manipulating space offered by modern technology. The perspective of The Night Journey is first-person, and we do not see any part of the avatar's body. Using the left stick of the game-pad, we can slowly wander through the monochrome landscape, blurred and out of focus. The right stick is responsible for the camera movement, which - again as in a game with a first-person perspective - is attached to the invisible body of the interactant's avatar. The $\mathrm{X}$ key has a rather unusual function. It is often called an ",action button” because pressing it most often allows one to perform tasks assigned to the „enter" key on a computer; however, there is no action in Bill Viola's installation. Pressing X makes the camera look inside the player's "soul" to see images not entirely related to the virtual space in which we are located. Sometimes, we feel like we are moving back or forth in time; eg. the building we are entering turns to ruin. Bill Viola adopts the mechanics of a sandbox game, but he also reworks it. There are no opponents, a defined goal or challenges, no dangers, and our action is, in fact, an "anti-action”, a retreat into the dream-like world of the self.

The Night Journey focuses on immersion. Bill Viola's work is intended for a single user entering a virtual space in the comfort of their home. The artist uses the strategy of reduction and reworks the

[8] More in-depth analysis of this project can be found in my book: Zanurzony. O sztuce Billa Violi, Kraków 2016.
[9] Experimental work-in-progress versions were shown in galleries around the world, and final release was published in 2018 for PC, Mac and Playstation platforms (USA only). 
usual features of a video game. His goal is not the deconstruction of its mechanics; instead, he aims at adopting them to create new space for media art, outside a gallery space.

Into the public sphere
Contemporary games not only make use of augmented reality, but also frequently incorporate public space, especially when it comes to mobile games. They become more and more popular because people spend more time outside their homes[10]: commuting, travelling for business and pleasure, and simply going out. The strategies used by game designers also seem to be rooted in artists' experiments. Among them, Rafael Lozano-Hemmer seems to be one of the most exciting ones. His projects are deeply rooted in science. In his art, he refers to IT and robotics, as well as audiovisual techniques. His projects are very diverse, from small installations for art galleries to spectacular ones in public spaces, which are often site-specific, eg. the Relational Architecture series, consisting of large-scale interactive works presented in many cities around the world.

All of his works share a participation-oriented attitude with a focus on cooperation, not only between man and machine, but also between people interacting with his works. The problem of supervision[11] and control with modern technologies seems to be his preferred topic. Therefore, cameras, motion detectors, trackers, and other types of sensors are almost always used in his works. Surface Tension (1992) is a fine example of a smaller work based on an intuitive interface similar to those found in XBOX or Playstation games based on an "invisible" interface, where gamepads are partly or completely replaced by "commands" given by the movements of a player's body. This work was originally designed as a set design for the Spanish theatre group Transition State Troupe, but was later exhibited as an independent installation. Viewers are confronted with an image of a giant eye, which, thanks to the use of motion sensors, accurately tracks the movement of the person in front of the screen.

Lozano-Hemmer used other sensors, eg. those recording a heartbeat. They can be found in Pulse Room (2006), Pulse Tank (2008), Pulse Spiral (2008) and Pulse Park (2008), as well as several later works from this series. In all of them, the rhythm of visitors' hearts is represented in different ways: eg. with flashing light bulbs or crashing waves. Currently, games also often rely on biointerfaces measuring various functions of the human body. Examples can be found in serious games used in medicine, training and psychometric evaluation.

Architectural installations seem to be most important for Lozano-Hemmer. The Able Skin (1997, with Emilio López-Galiacho) is an example of an interactive info-architecture designed for exhibition in
[10] This notion has to be reevaluated in the times of pandemic.

[11] M. Ożóg, Surveilling the surveillance society: The case of Rafael Lozano-Hemmer's Installations, [in:]
Conspiracy Dwellings: Surveillance in contemporary art, eds. O. Remes, P. Skelton, Cambridge 2010, s. $95-111$. 
a gallery. The viewer can explore three-dimensional models of buildings. The more elaborate Displaced Emperors (1997) was installed in the public space of Linz castle. Visitors can "touch" the façade displayed on the walls of the building with a virtual hand, thanks to the use of motion sensors. Another form of interaction was designed for Vectorial Elevation (1999), created to celebrate the coming of the year 200o. The work consisted of eighteen powerful spotlights controlled by a webbased interface, producing a kind of phantom sculpture visible from places located dozens of kilometres from Zócalo Square in Mexico City, where the work was exhibited. One of the most interesting works of the series is Body Movies (2001), a site-specific installation designed for a central square in Rotterdam. This Dutch city has been rebuilt from wartime destruction in a way that does not encourage its citizens to meet in the public sphere. Lozano-Hemmer decided to change this, using the façade of a huge multiplex cinema in the centre of the metropolis. It was covered with white plastic semi-transparent film, on which photographs of people from around the world were projected. However, they were visible only in the areas covered by the shadows of people moving around the building within the area illuminated by high-efficiency xenon lamps. To change the set of images to a new configuration, strangers had to work together to find and reveal all the hidden photographs. Many of the people interacting with the piece organized in groups, not only to follow the artist's instructions, but to use the interface in a subversive way, eg. creating short shadow-play scenes on a screen provided by the façade of the building.

Elements of game-like mechanics are often present in works by Blast Theory, a British cooperative experimenting with games, interactive theatre and cinema, geo-media and many other technologies.

In the early 1990s, the ensemble was an experimental theatre troupe not necessarily interested in high-tech. By the end of the decade, they produced The Kidnap (1998), a groundbreaking project in which ten volunteers participated in a real-life theatre/game. Two of them were kidnapped and placed in a hideout, while the "audience' could follow the fictional story on a specially-designed website.

In Desert Rain (1999), Blast Theory members used virtual reality and computer game mechanics for the first time, to create a hybrid event that allows participants to take part in an operation in the Persian Gulf. The inspiration for this original performance was Jean Baudrillard's controversial essays about American military action in the Middle East.

Can You See Me Now? (2001) using the ARG (alternate reality game) formula was based on the use of geolocative media. Blast Theory's work, awarded at the Ars Electronica Festival, is considered alongside BotFighters (also 2001) to be a pioneering ARG-type project. The mechanics of the game is very simple and resembles hide-and-seek, which is often played by children. The difference is that participants move in two spaces at the same time: players acting as online escape hunters traversing the actual urban space. The juxtaposition of the two spheres 
was possible thanks to the use of palmtops, and the game has become a prototype for many later realizations using today's smartphones or tablets with GPS.

Blast Theory themselves alluded to their pioneering project in Uncle Roy All Around You (2003), in which players are searching for the office of Uncle Roy, again on the borderline of the real and virtual worlds. The group follows the rapidly-changing market of mobile devices looking for unexpected applications for new gadgets. Their subsequent realizations are not only more technologically complex, but also convey increasingly sophisticated content. In 2009, one of their works, Ulrike and Eamon Compliant, was shown during the Venice Biennale, while I'd Hide You (2012) was presented twice at Sheffield Doc/Fest in 2013 and 2014.

Art intersects with the game industry on a variety of levels. Triple-A projects are becoming more and more complex and vigorously look for a new audience. Games by Naughty Dog, Quantic Dreams, Polish CD Project and other big studios are often complex narratives that can rival art house cinema. For smaller companies, venturing into the realm of art can often be a chance to compete with their bigger competitors. On the other hand, artists do not ignore games as an important part of the contemporary mediasphere. They will surely continue to reinvent games, deconstruct them, play them, and finally, inspire game designers to create more elaborate and challenging projects available for larger and more mainstream audiences.

Broadhurst S., Machon J., Performance and Technology: Practices of virtual embodiment and interactivity, Houndmills - New York 2011

Fujihata M., Anarchive $n^{\circ} 6$ - Masaki Fujihata, Paris 2016

Jagoda P., Experimental Games: Critique, play, and design in the age of gamification, Chicago - London 2020

Lehdonvirta V., Castronova E., Virtual Economies: Design and analysis, Cambridge 2014

Ma M., Oikonomou A., et al, Serious Games and Edutainment Applications, London - Dordrecht - New York 2011

Ożóg M., Surveilling the surveillance society: The case of Rafael Lozano-Hemmer's installations, [in:] Conspiracy Dwellings: Surveillance in Contemporary Art, eds. O. Remes, P. Skelton, Cambridge 2010, pp. 95-111

Phillips W., A Composers Guide to Game Music, Cambridge 2017

Pitrus A., Zanurzony. O sztuce Billa Violi, Kraków 2016 